This item was submitted to Loughborough's Research Repository by the author.

Items in Figshare are protected by copyright, with all rights reserved, unless otherwise indicated.

\title{
Mechanically robust transparent anti-icing coatings: Roles of dispersion status of Titanate nanotubes
}

PLEASE CITE THE PUBLISHED VERSION

https://doi.org/10.1002/admi.201800773

\section{PUBLISHER}

(c) Wiley

\section{VERSION}

AM (Accepted Manuscript)

\section{PUBLISHER STATEMENT}

This work is made available according to the conditions of the Creative Commons Attribution-NonCommercialNoDerivatives 4.0 International (CC BY-NC-ND 4.0) licence. Full details of this licence are available at: https://creativecommons.org/licenses/by-nc-nd/4.0/

\section{LICENCE}

CC BY-NC-ND 4.0

\section{REPOSITORY RECORD}

Wu, Xinghua, Yuxin Tang, Vadim Silberschmidt, Peter Wilson, and Zhong Chen. 2019. "Mechanically Robust Transparent Anti-icing Coatings: Roles of Dispersion Status of Titanate Nanotubes". figshare. https://hdl.handle.net/2134/36051. 


\title{
Mechanically Robust Transparent Anti-Icing Coatings: Roles of Dispersion Status of Titanate Nanotubes
}

\author{
Xinghua Wu, Yuxin Tang, Vadim V. Silberschmidt, Peter Wilson, and \\ Zhong Chen*
}

Ice accretion on automobiles, aerospace components, precision instruments, and photovoltaic devices detrimentally affect their performance and increase the maintenance cost. Despite significant efforts devoted to the investigation of anti-icing coatings in the past decades, mechanically robust and transparent anti-icing coatings are rarely reported. In this study, titanate nanotubes are used as filler to prepare mechanically robust anti-icing coatings with a sol-gel method. Specially, the effect of dispersion status of investigated. The optimized smooth, transparent coating exhibits higher water repellency and better anti-icing performance in terms of ice-adhesion strength, icing delay time, and ice-nucleation temperature than the rough one. Much higher hardness and scratch resistance than that of commercially available icephobic or anti-icing coatings is obtained on the smooth, transparent sample; the coating also presents good adhesion to the substrate. nanotubes on the transmittance, surface roughness, and water repellency is

SLIPS (slippery liquid infused porous surface) inspired by nepenthes. ${ }^{[2]}$ However, conventional schemes such as creating a roughened surface with trapped air or lowsurface-energy liquid in order to enhance water repellency and reduce ice adhesion are not sufficient to produce robust antiicing coatings. ${ }^{[3]}$ Water repellency at low temperature and suitable mechanical properties are two principal requirements for the future development of anti-icing coatings. To date, the study of mechanical properties of anti-icing coatings has not been widely reported. Among a few available publications, Wang et al. ${ }^{[4]}$ reported a superhydrophobic steel surface with anti-icing properties. The surface could withstand a peeling test with $3 \mathrm{M}$ adhesive tape and abrasion by 400 grid $\mathrm{SiC}$ sandpaper with a scratch length of $110 \mathrm{~cm}$. Chen et al. ${ }^{[5]}$ developed an anti-icing

\section{Introduction}

Anti-icing coatings are highly valued for preventing or alleviating adverse consequences of ice accretion on airplanes, marine structures, satellites, weapon systems, and energy-harvesting devices. In the past two decades, tremendous efforts have been devoted to the study of anti-icing performance of superhydrophobic coatings inspired by the lotus effect ${ }^{[1]}$ and

X. H. Wu, Dr. Y. Tang, Prof. Z. Chen

School of Materials Science and Engineering Nanyang Technological University

50 Nanyang Avenue, Singapore 639798, Singapore E-mail: aszchen@ntu.edu.sg

Prof. V. V. Silberschmidt

Wolfson School of Mechanical

Electrical and Manufacturing Engineering Loughborough University Loughborough, Leicestershire LE11 3TU, UK

Prof. P. Wilson

Institute for Marine and Antarctic Science University of Tasmania Hobart 7000, Australia

Prof. P. Wilson Honors College

University of South Florida Tampa, FL 33620, USA coating with a self-lubricating-liquid water layer, the anti-icing layer exhibited low ice-adhesion strength of around $63 \pm 11 \mathrm{kPa}$ after ten cycles of an abrasion test with a 10000 mesh sandpaper. However, some of these mechanical abrasion tests were not carried out following any ISO or ASTM standards, so it becomes difficult to compare and evaluate the claimed results. Menini et al. ${ }^{[6]}$ deposited a poly(tetrafluoroethylene) (PTFE) coating on aluminum alloys and the surface presented iceadhesion strength of $\approx 100 \mathrm{kPa}$ with good adhesion to substrate according to the ASTM D3359-02 cross-cut test. Huang et al. ${ }^{[7]}$ fabricated an icephobic coating by mixing silica sol and fluorinated acrylate copolymers. The hybrid film exhibited pencil hardness of $4 \mathrm{~B}$ and cross-cut adhesion of $0 \mathrm{~B}$. Kimura et al. ${ }^{[8]}$ claimed a new icephobic paint with pencil hardness of $2 \mathrm{H}$. Mazzola $^{[9]}$ reported an aeronautical livery icephobic coating and compared the nanoindentation results of the coating with those for a commercial coating. Both coatings exhibited a hardness of $\approx 150 \mathrm{MPa}$ and modulus of $\approx 4.8 \mathrm{GPa}$. Sojoudi et al. ${ }^{[10]}$ reported an icephobic bilayer polymer film prepared with initiated chemical vapor deposition (iCVD). The film presented an ice-adhesion strength of $\approx 150 \mathrm{kPa}$, a hardness of $479.0 \pm 7.0 \mathrm{MPa}$, and elastic modulus of $19.1 \pm 1.2 \mathrm{GPa}$ thanks to its dense structure.

Besides mechanical performance, transparency of anti-icing coatings is another essential consideration for applications such as windows, windshields of automobiles, instruments, sensors, cameras, satellites, weapon systems, and photovoltaic devices. Although transparency is very important, transparent anti-icing coatings are seldom reported, except for some commercial antifreeze proteins, liquids, or agents, ${ }^{[11]}$ however, these 


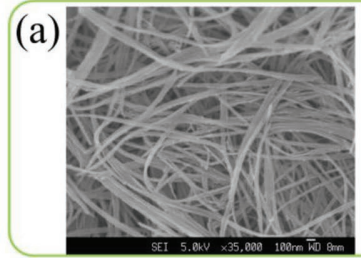

(b)

(d)

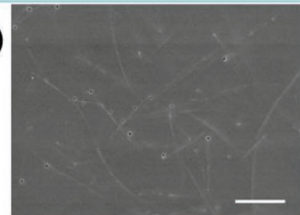

(f)

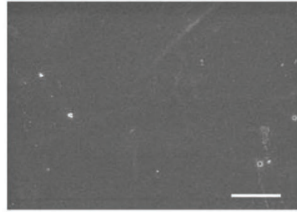

(g)

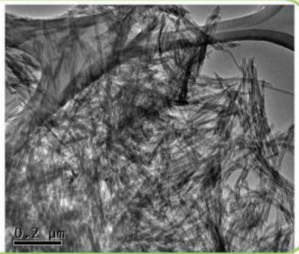

(e)

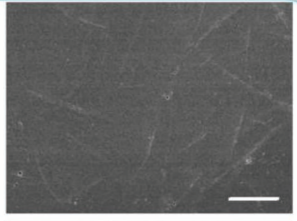

(h)

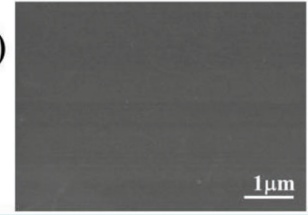

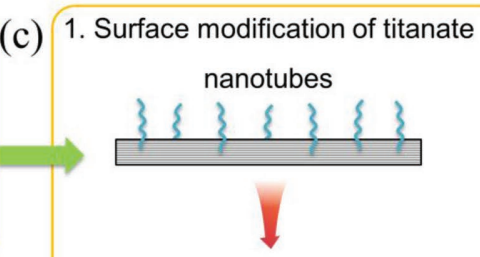

2. Added to the sols and stirring

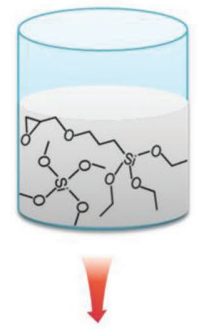

3. Spraying coated onto the glass substrate with post-heat treatment

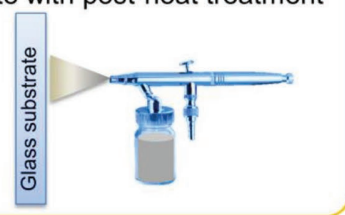

Figure 1. a) FESEM image and b) TEM images of elongated titanate nanotubes; c) schematic illustrations of preparation method of titanate nanotube coatings, and FESEM images of prepared titanate nanotube coatings with different stirring times: d) T_1, e) T_2, f) T_4, g) T_6, and h) T_7.

coatings are mechanically weak. An earlier study of transparent anti-icing coating was conducted by Kimura et al., ${ }^{[8]}$ and one of their reported coatings was water-repellent and transparent. However, it had a mild cream color. Wong et al..$^{[2]}$ first fabricated SLIPS, which demonstrated low ice adhesion, and claimed that by choosing a substrate and a lubricant liquid with matching refractive indices, coatings with high transparency could be achieved. Recently, a US patent application (US20180016383A1) revealed a transparent anti-icing coating that contains uniform distribution of particles and asymmetric templates. ${ }^{[12]}$ Although the coating exhibited a kinetic delay of water freezing and depression of an ice melting point, the ice-adhesion strength of the coating was not reported. To date, fabrication of a transparent anti-icing coating with good mechanical properties remains a challenge. However, due to its great importance for various practical applications discussed above, continued research efforts are expected to be channeled into this area.

Nanosized metal oxides with unique low-dimensionality (0D, 1D, 2D) and physical/electrical properties have recently become a hot topic in various research areas. ${ }^{[13]}$ For instance, $\mathrm{TiO}_{2}$ nanobelts were well-studied for self-cleaning and antifogging applications. ${ }^{[14]}$ In 2014, Tang et al. ${ }^{[15]}$ reported for the first time a mechanical force-driven method to grow elongated titanate nanotubes with lengths up to tens of micrometers. Due to the unique structure of nanotubes, they are able to not only enhance mechanical properties of the coatings, but also provide a perfect site for air trapping or storage of hydrophobic additives. Using low-surface-energy polymers, hydrophobic or superhydrophobic coating with nanotubes can be achieved. Recently, carbon nanotubes were reported in the design of anti-icing coating. ${ }^{[16]}$ In this study, the elongated titanate nanotubes were employed to fabricate anti-icing coatings. One unique feature of this study is application of mechanical stirring during the sol preparation to fabricate coatings with different magnitudes of surface roughness. The effect of surface roughness on light transmittance and anti-icing performance was analyzed. Specifically, the anti-icing performance of coated glass slides, including ice-adhesion strength, icing delay time, and icing temperature were examined and compared with uncoated glass slides. Furthermore, the resultant coatings were transparent and mechanically strong, thus promising potential applications in aerospace, precision instruments, energy-harvesting devices, etc.

\section{Results and Discussions}

The effect of surface roughness on wetting characteristics of a surface has been studied. It is generally accepted that roughening, or texturing, a hydrophobic surface leads to superhydrophobic surfaces, according to the fundamental wetting theory. ${ }^{[17]}$ In this work, mechanical stirring was employed to change a dispersion state of the nanotube fillers and, as a result, the surface roughness. The transmittance, water wettability, anti-icing performance, and mechanical properties of hydrophobic coatings with different surface roughness were investigated.

\subsection{Effect of Stirring Time on Surface Topology}

Field emission scanning electron microscopy (FESEM) and transmission electron microscopy (TEM) images (Figure 1a,b) 
show detailed elongated titanate nanotubes prepared by the hydrothermal reaction. Nanotubes with the lengths up to several tens of micrometers were fabricated and embedded in the sol-gel matrix to obtain hydrophobic coatings as illustrated in Figure 1c. The surface morphology of the prepared titanate nanotube coatings with different stirring times was examined with FESEM (see Figure 1d-h). The surfaces were covered with intertwined titanate nanotubes, forming nanosized pores.

Fourier transform infrared (FTIR) spectra of the $1 \mathrm{~d}$ stirring (T_1) and the $7 \mathrm{~d}$ stirring $\left(\mathrm{T}_{-} 7\right)$ coatings are shown in Figure 2. The two coatings presented exactly the same absorption peaks of $\mathrm{Si}-\mathrm{O}-\mathrm{Si}\left(444 \mathrm{~cm}^{-1}\right),{ }^{[18]} \mathrm{Ti}-\mathrm{O}-\mathrm{Ti}\left(\approx 690\right.$ and $\left.582 \mathrm{~cm}^{-1}\right),{ }^{[19]}$ $\mathrm{Si}-\mathrm{C}\left(\approx 775 \mathrm{~cm}^{-1}\right), \quad \mathrm{Si}-\mathrm{O}\left(910 \mathrm{~cm}^{-1}\right)$, overlapping $\mathrm{Si}-\mathrm{O}-\mathrm{Si}$ and $\mathrm{Si}-\mathrm{O}-\mathrm{C}$ (broadband in the range of $1000-1100 \mathrm{~cm}^{-1}$ ), ${ }^{[18]}$ $\mathrm{C}-\mathrm{F}\left(1273,1203\right.$, and $\left.1116 \mathrm{~cm}^{-1}\right),{ }^{[20]} \mathrm{C}-\mathrm{O}\left(1739 \mathrm{~cm}^{-1}\right),{ }^{[21]}-\mathrm{CH}_{3}$ (2879 and $\left.2940 \mathrm{~cm}^{-1}\right),{ }^{[18]}$ and absorbed water $\left(1641 \mathrm{~cm}^{-1}\right.$ and broadband peaked at $\left.3434 \mathrm{~cm}^{-1}\right) \cdot{ }^{[22]}$ This is expected since the two coatings are derived from the same precursor.

Atomic force microscopy (AFM) images in Figure 3 show a clear trend of decreasing surface roughness with the increasing stirring time. The level of surface roughness of T_1 was $365.85 \mathrm{~nm}$, and that for T_7 was $5.66 \mathrm{~nm}$-a reduction by two orders of magnitude. A decrease in surface roughness with time indicates better dispersion of titanate nanotubes, overcoming agglomeration forces (van der Waals bonding and hydration bonding) in the sol and potentially leading to better

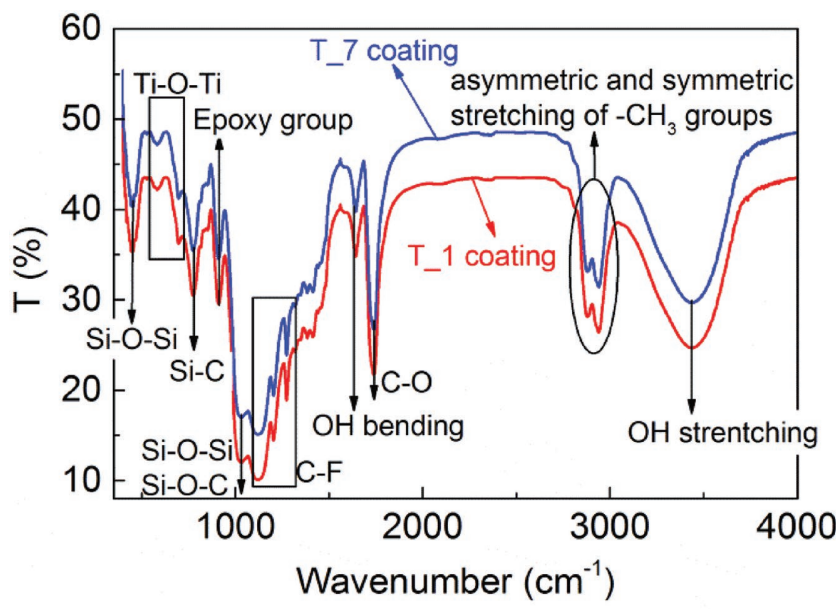

Figure 2. FTIR spectra of the T_1 and T_7 coatings mixed in $\mathrm{KBr}$ tablets with weight ratio of 1:20.

mechanical reinforcement and more uniform distribution with low surface energy.

To observe clearly dispersion of the filler in the coatings, T_1, T_5, and T_7 samples were examined with TEM (Figure 4). The diameter and aspect ratio of the titanate nanotube are about $116 \pm 30 \mathrm{~nm}$ and 265 , respectively. ${ }^{[13 c]}$ Titanate nanotubes in the $T_{-} 1$ sample agglomerated into large clusters with sizes of a few micrometers. The flow of the sol in response to the external
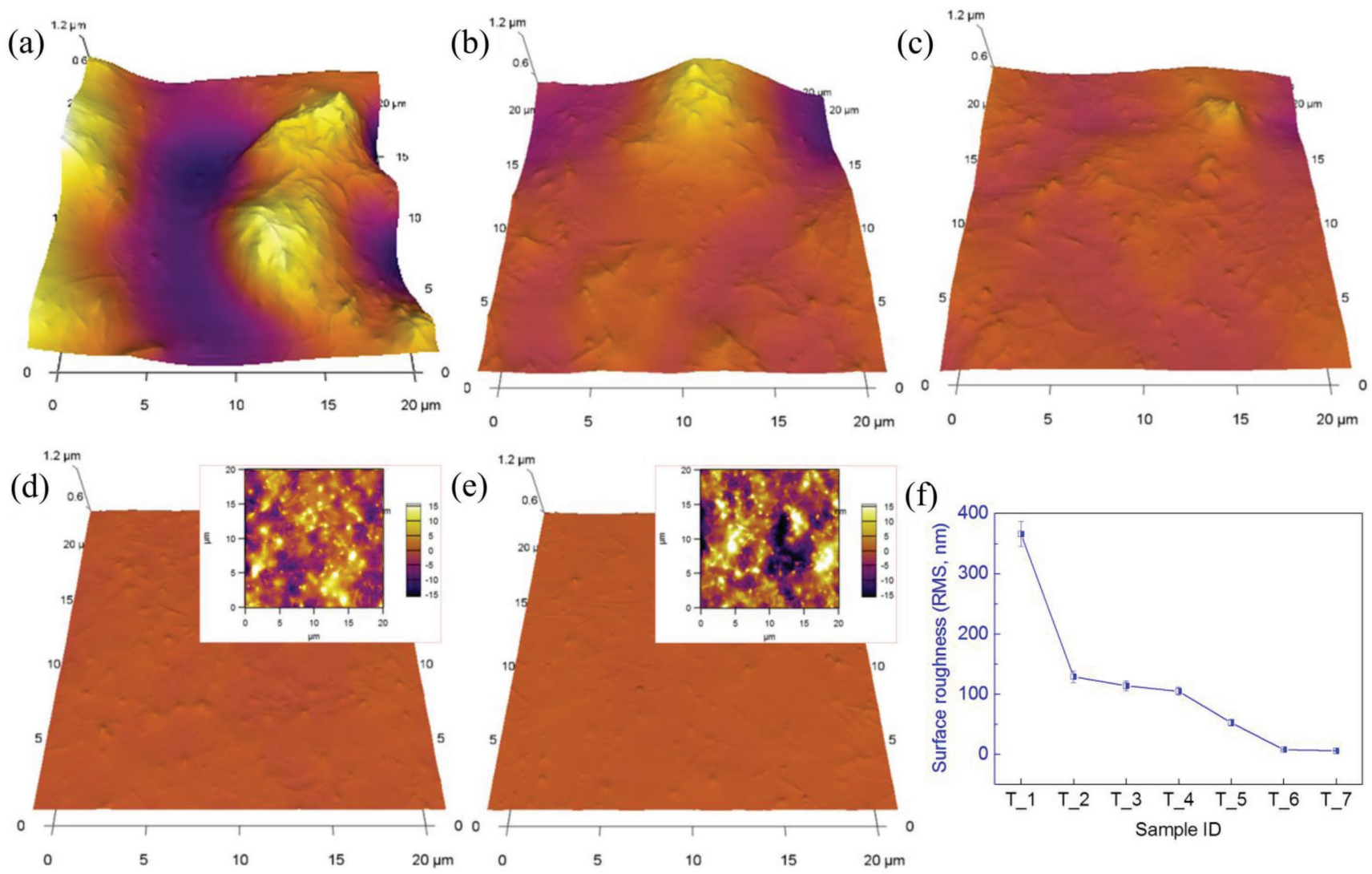

Figure 3. AFM images of a) T_1, b) T_2, c) T_4, d) T_6, and e) T_7 samples (the scale bar for these images is $1.2 \mu \mathrm{m}$ ). The inset images of (d) and (e) show fine features of relatively smooth surfaces (the scale bar is $30 \mathrm{~nm}$ ). f) Measured root-mean-square surface roughness of these samples. 

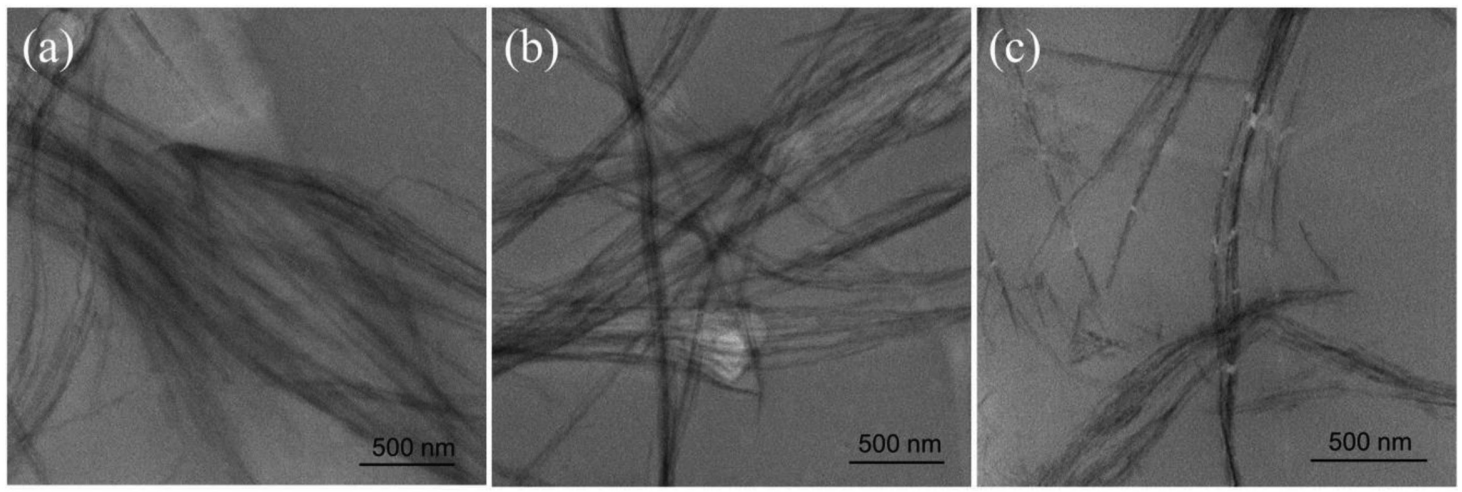

Figure 4. TEM images of a) $T \_1$, b) $T \_5$, and c) $T_{-} 7$ coatings with same amount of titanate nanotubes but different dispersion status.

mechanical force gradually drove the dispersion of nanotubes, and more uniform distributions of them in the coatings are observed in the TEM images of the T_5 and the T_7 samples. Besides the mechanical stirring force, the addition of the lowsurface-energy $\quad 1 \mathrm{H}, 1 \mathrm{H}, 2 \mathrm{H}, 2 \mathrm{H}$-perfluorooctyltriethoxysilane (PFOTES), which reacted with $-\mathrm{OH}$ groups on nanotube surfaces, significantly increased the steric or entropic repulsion energy, contributing to dispersion of the nanotubes. Here, mechanical agitation, which is a common method to mix fillers in sols, was for the first time introduced in the sol-gel system to achieve de-agglomeration of nanotubes and obtain coatings with different surface roughness.

\subsection{Effect of Surface Roughness on Coating Transmittance}

It is well known that surface unevenness affects transmittance of visible light. Researchers have found that level of agglomeration of the nanoparticles in coatings changed their transmittance. ${ }^{[23]}$ Chang et al. ${ }^{[24]}$ reported that increased surface roughness resulted in a decrease in transmittance. In the current work, the extent of transmittance of the coatings increased with the increasing stirring time as shown in the detailed digital images in Figure 5a. To investigate the scattering effect of these coatings, digital images were taken employing the setup illustrated schematically in Figure 5b; the samples were placed (a)

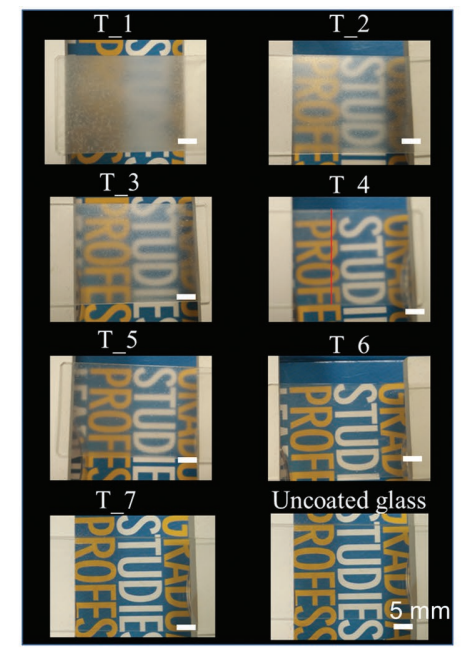

(b)

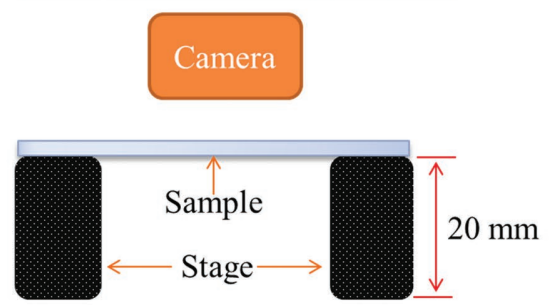

(c)

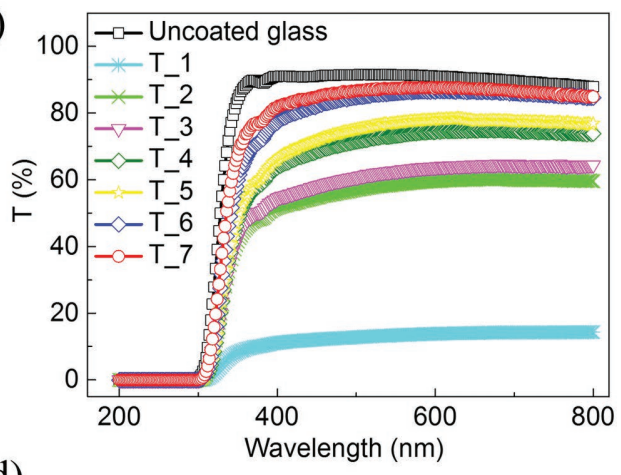

(d)

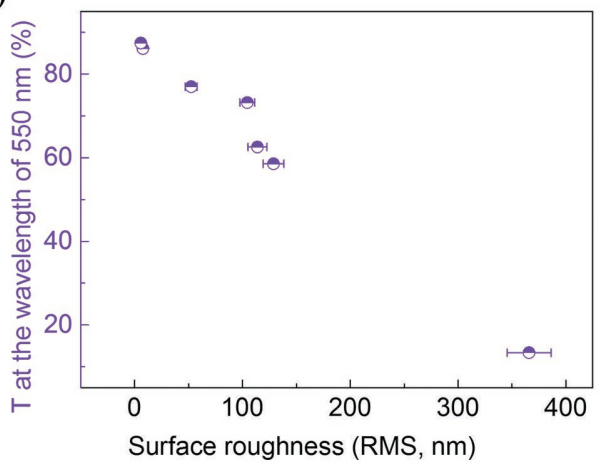

Figure 5. a) Digital images through coated and uncoated glass substrates; b) schematic illustration of test setup; c) transmittance of uncoated and coated with titanate nanotubes coatings glass; d) transmittance of coated glass substrates at wavelength of 550 nm and corresponding surface roughness. 


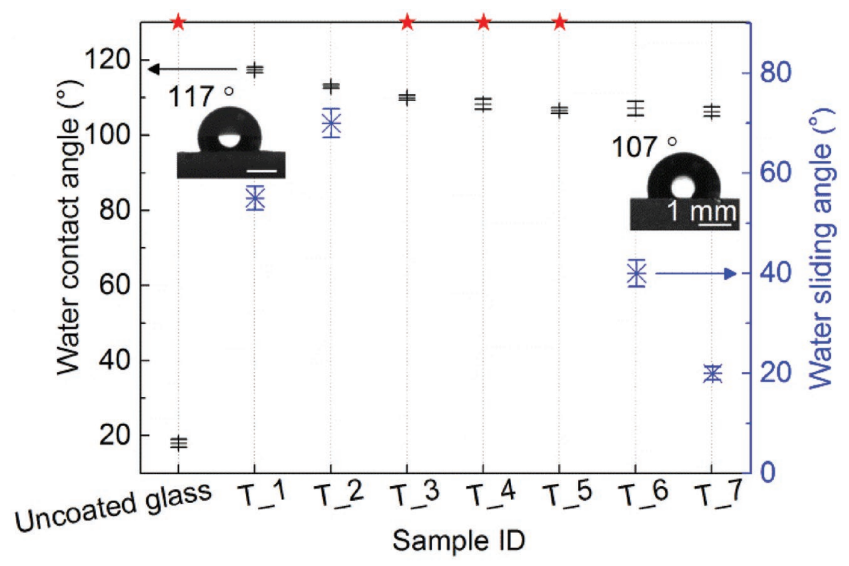

Figure 6. Apparent water contact angles and sliding angles of uncoated glass and titanate nanotube coatings, (insets are microscopic images of water droplets on T_1 and T_7 coating surfaces; symbol $\star$ indicates no sliding even when the plate was tilted by $90^{\circ}$.

$2 \mathrm{~cm}$ away from the colored logo image. The T_1 sample was translucent, with transmittance lower than $20 \%$. Continuous stirring led to an increase in the transmittance of samples: the level of transmittance for the T_6 and T_7 samples were comparable to that of uncoated glass. Levels of transmittance measured with a UV-vis spectrometer (Figure 5c) also confirm the increased transmittance along with increased stirring time. The data for transmittance at the wavelength of $550 \mathrm{~nm}$ are plotted against the values of surface roughness in Figure $5 \mathrm{~d}$ : a linear decline can be observed, indicating the dominating influence of surface roughness on transmittance. Thus, the decrease in surface roughness led to a significant increase in the transmittance of coatings. In other words, good dispersion of the nanotube clusters reduces significantly the scattering of visible light, resulting in a high transparency of the T_6 and T_7 samples.

\subsection{Water Wettability of Titanate Nanotube Coatings}

A separate study was implemented to assess water wettability of the developed coatings:

Figure 6 shows water contact angles and sliding angles of uncoated glass and the titanate nanotube coatings. The sliding and pinning behaviors of a $10 \mu \mathrm{L}$ droplet on the coating coated glass and uncoated glass can be seen in Video S1 (Supporting Information) (played at $8 \times$ accelerated speed). Uncoated glass is hydrophilic, exhibiting a low water contact angle with no sliding. The T_1 sample presented the highest water contact angle of around $117^{\circ}$ and a sliding angle of $54^{\circ}$. This indicates a likely mixed Cassie-Wenzel state, with some trapped air pockets mixed with complete wetting of the surface asperities. As the stirring time increased, the surface roughness decreased and the contact angle decreased slightly. The mixed wetting condition became more and more dominated by the Wenzel contact, explaining the observed increase in the sliding angle. After $3 \mathrm{~d}$ of stirring, the wetting mode is likely to be fully in the Wenzel regime, and water droplet could not roll off by its gravity force, even when the substrate was titled by $90^{\circ}$. With a further increase in the stirring time, the surface became very smooth; under such condition the water adhesion becomes dependent on the surface energy only. The water droplet could slide off and the sliding angle decreased with increased smoothness. The sliding behavior on the T_6 and the T_7 samples can be explained by the interfacial slippage between the water droplet and the coating surface. ${ }^{[3 c]}$ Based on our studies, it can be concluded that for a hydrophobic coating, surface topology dominates the sliding behavior, or water repellency, of coatings. In particular, the T_7 sample exhibited a water contact angle of $107^{\circ}$ and the lowest sliding angle at $20^{\circ}$, presenting good waterrepellent properties.

\subsection{Anti-Icing Performance of Titanate Nanotube Coatings}

The wettability tests were followed by analysis of anti-icing performance; Figure 7a demonstrates the measured ice-adhesion strength with the coated and uncoated glass substrates at -15 and $-20{ }^{\circ} \mathrm{C}$. Compared to an uncoated glass, threefold lower ice-adhesion strength was measured for the titanate nanotube coatings.

The ice-adhesion strengths of these coatings fell into the range of 57-87 $\mathrm{kPa}$, below a well-accepted threshold value of $100 \mathrm{kPa}$ for icephobic coatings. ${ }^{[3 \mathrm{c}, 25]}$ These levels of adhesion strength are only around half of the reported ice-adhesion strength on carbon nanotube reinforced polymer composites. ${ }^{[26]}$ Although the surface roughness of titanate nanotube coatings varies greatly depending on the stirring time, only a slight change in the ice-adhesion strength was observed. Researchers in the past attempted to establish a relationship between the ice-adhesion strength and the water contact angle or the work of adhesion with water, ${ }^{[27]}$ however, the surface energies of the tested surfaces were not kept the same. Here, the apparent surface energy, apparent water contact angle, and ice-adhesion strength of samples are compared in Figure 7b. It was found that the apparent surface energy and ice-adhesion strength presented a similar trend, significantly different from that for the apparent water contact angle, implying a strong influence of the surface energy on the ice-adhesion strength of samples. Menini and Farzaneh ${ }^{[28]}$ defined four factors that affected the ice-adhesion strength: (i) intermolecular forces (such as covalent, electrostatic, and van der Waals forces); (ii) mechanical-interlocking-induced adhesion; (iii) diffusion; and (iv) the presence of a liquid-like layer at the ice-substrate interface. In this study, due to the mountain-valley type structure of titanate nanotube coatings, no significant mechanical interlocking was observed. The low surface energies of these coatings allowed lower intermolecular forces and lower diffusion, resulting in low ice-adhesion strength. It is noticed that both the T_1 and T_7 samples presented the lowest iceadhesion strength; however, due to their greatly different surface roughness, they may present different mechanisms of ice adhesion. The low ice-adhesion strength of the T_1 surface was mainly due to partial wetting, allowing air-trapping inside the coatings. Once iced formed, the trapped air could serve as an initial interfacial crack at the ice-solid interface, reducing the energy of separation. ${ }^{[29]}$ On the other hand, the reason for the low ice-adhesion strength of the T_7 surface primarily lies in the low contact angle hysteresis on smooth surfaces thus 
(a)
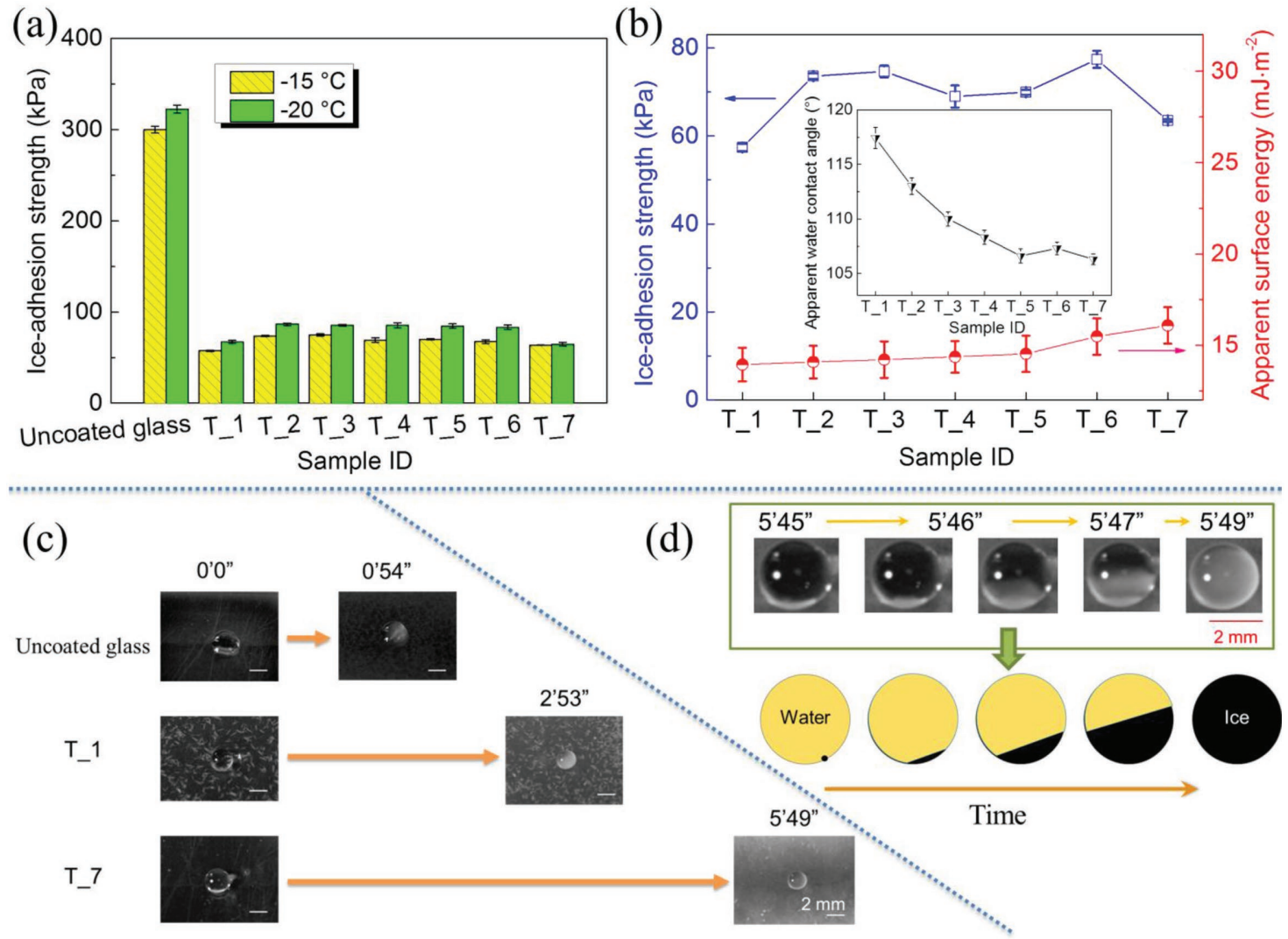

Figure 7. a) Ice-adhesion strength of coated and uncoated glass at -15 and $-20^{\circ} \mathrm{C}$, b) comparison of measured ice-adhesion strengths and apparent surface energies of titanate nanotube coatings (insets show apparent water contact angles); c) icing-delay times of the uncoated glass, T_1, and the T_7 samples at $-15{ }^{\circ} \mathrm{C}$; d) time-sequential digital images captured with a high-speed camera during icing-delay test and schematic illustration of ice growth on water-solid interface.

allowing minimal contact-line pinning. ${ }^{[30]}$ In particular, nearly no change in the ice-adhesion strength of the T_7 sample was observed at different temperatures after testing for more than five times, indicating its good anti-icing reliability.

The icing-delay times of the uncoated glass, the T_1 and the $\mathrm{T} \_7$ samples at $-15^{\circ} \mathrm{C}$ are shown in Figure 7c. It took $3 \mathrm{~min}$ and $17 \mathrm{~s}$ for the temperature of all the samples to reach $-15^{\circ} \mathrm{C}$. The droplet on the uncoated glass surface started to freeze first after 54 s, followed by the T_1 sample (173 s). The longest icing delay time was observed on the T_7 sample, which was nearly 6 min.

During the icing-delay test, ice nucleation on the three-phase contact line was observed regardless of the surface roughness (see Video S2, Supporting Information, frame rate $\mathrm{s}^{-1}$ : 28.6). Figure $7 \mathrm{~d}$ provides the time-sequential digital images captured with a high-speed camera during the icing-delay test and illustrated the ice-growing process on the water-solid interface. This result is consistent with previous reports, ${ }^{[31]}$ demonstrating that heterogeneous nucleation along a three-phase contact line is a preferred option as compared to the solid-liquid interface.

To further study the anti-icing performance, the icing temperature of the T_1 and T_7 samples was measured and compared with that of the uncoated sample; Figure 8 a shows the results for icing temperatures tested for 500 cycles. Statistical analysis of heterogeneous nucleation behavior of supercooled water droplets on these samples according to our previous report ${ }^{[31 a]}$ is given in Figure $8 \mathrm{~b}-\mathrm{h}$. The distribution of icing temperatures was plotted by binning the measured data with a bin width of $0.2{ }^{\circ} \mathrm{C}$. The resulted freezing distributions of each sample as a function of the temperature are shown in Figure $8 \mathrm{~b}-\mathrm{d}$ and fitted with the Gauss equation. The Gauss peak temperature for the maximum freezing events for each sample is shown in Figure 8f. The freezing probability can be defined as Equation (1)

$P=\frac{N_{i}}{N_{0}}$

where $N_{i}$ is the freezing event in the $i$ th bin and $N_{0}$ is the total number of icing events (500 in the current study). The corresponding temperature-survival curve defined as $F(t)^{[32]}$ was employed to analyze the freezing probability distributions as shown in Equation (2)

$F(t)=\frac{N(t)}{N_{0}}$

where $N(t)$ is the unfrozen events at temperature $t$; the obtained results are shown in Figure 8e. In some reports, the temperature $t_{0.5}$, at which $F(t)=0.5$, was used as the ice-nucleation 
(a)

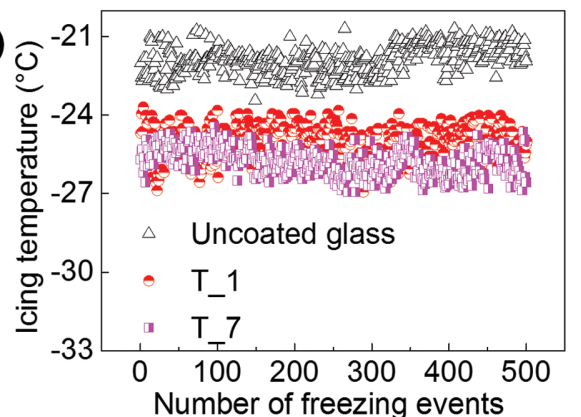

(b)

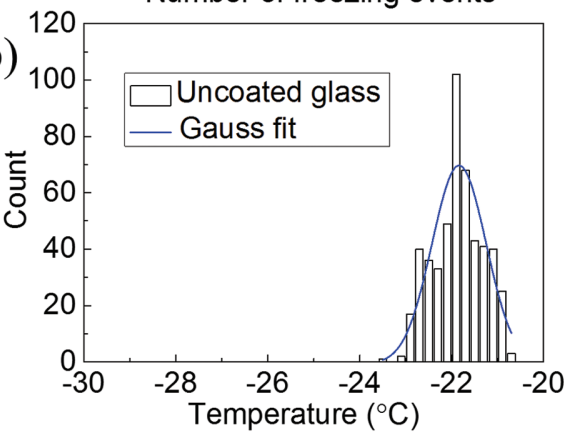

(c)

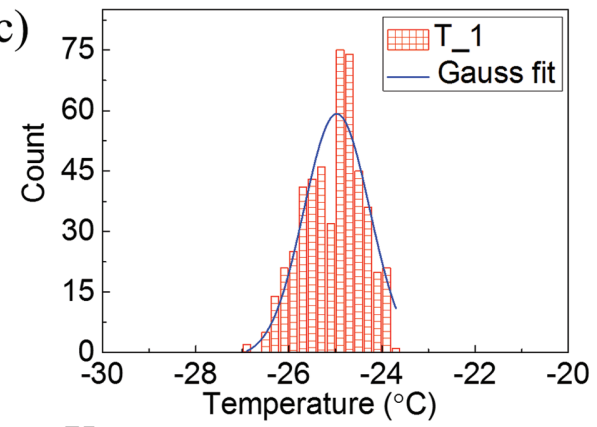

(d)

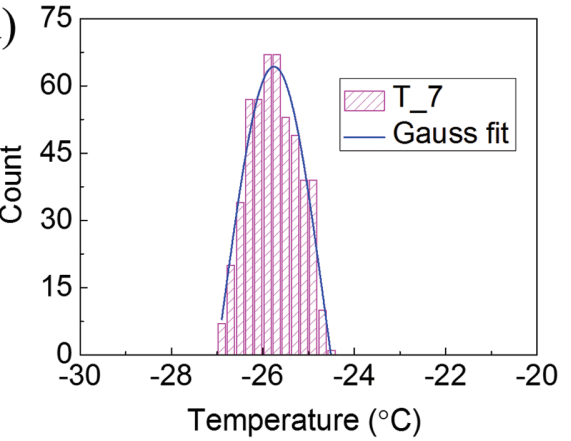

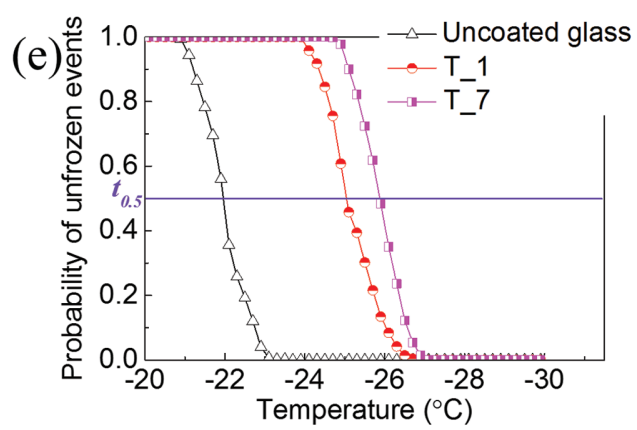

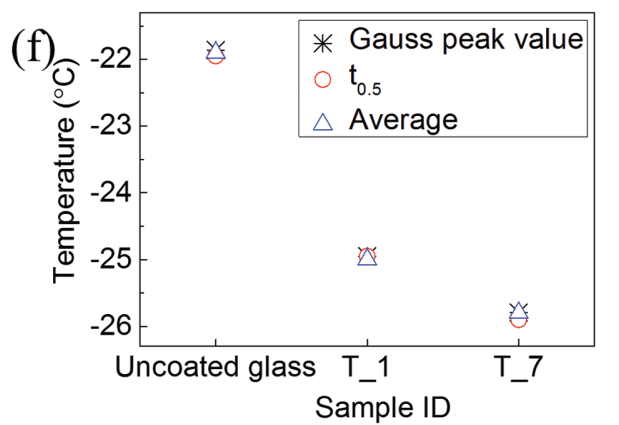

(g)

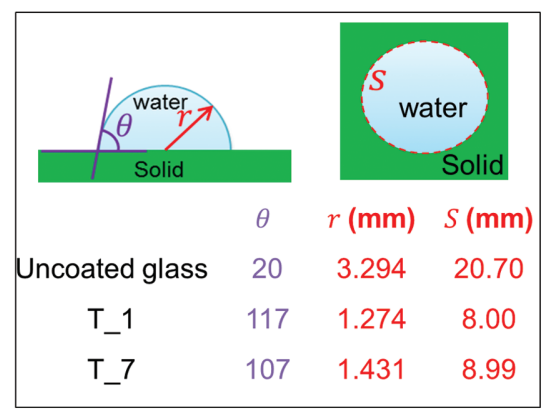

(h)

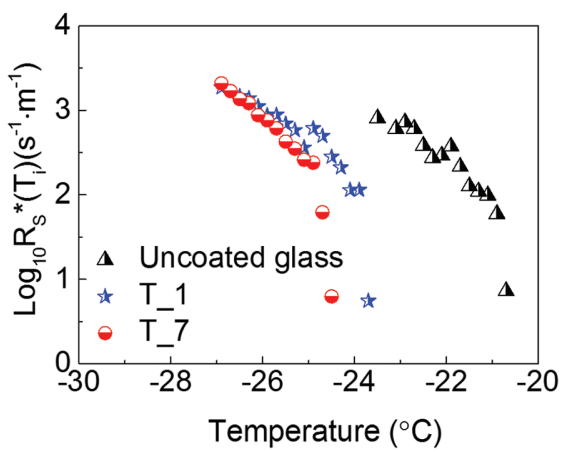

Figure 8. a) Ice-nucleation temperature of $T_{-} 1, T_{-} 7$ sample and uncoated glass; b) histogram of freezing events on uncoated glass, d) T_1 c) and T_7 samples with bin width of $0.2{ }^{\circ} \mathrm{C}$; e) temperature-survival curves of uncoated glass, T_1 and T_7 samples; f) schematic illustration of water contact angle and corresponding radius and length of three-phase contact line with calculated values for uncoated glass, T_1, and T_7 samples; g) the linenucleation rate of the uncoated glass, T_1 and T_7 samples.

temperature. A comparison of the Gauss peak temperatures obtained from Figure $8 \mathrm{~b}-\mathrm{d}$ and $t_{0.5}$ shown in Figure $8 \mathrm{e}$ demonstrates their perfect agreement (Figure $8 \mathrm{f}$ ). The average values of the icing temperature of the uncoated glass, the T_1 and the T_7 samples were $-21.9 \pm 0.5,-25.0 \pm 0.6$, and $-25.8 \pm$ $0.5{ }^{\circ} \mathrm{C}$, respectively. Compared to the icing temperature of the uncoated glass, a large decrease was clearly identified for the T_1 and the T_7 samples.

Additionally, the line ice-nucleation rate $R_{\mathrm{S}} *\left(T_{i}\right)$ of the uncoated glass, T_1 and T_7 samples was investigated based on the above freezing probability distributions as shown in Equation (3). The statistical nucleation rate $R\left(T_{i}\right)$ at $T_{i}$ was binned with a width of $\Delta T_{i}$, which contains $n_{i}$ freezing events, then

$$
R\left(T_{i}\right)=\frac{c n_{i}}{\Delta T_{i}\left(\frac{n_{i}}{2}+\sum_{j>i} n_{j}\right)}
$$

where $c$ is the cooling rate $\left(5^{\circ} \mathrm{C} \min ^{-1}\right.$ in our experiment), $\sum_{j>i} \mathrm{n}_{j}$ is the sum of unfrozen icing events. The corresponding line nucleation rate can be expressed as Equation (4) 
(a)

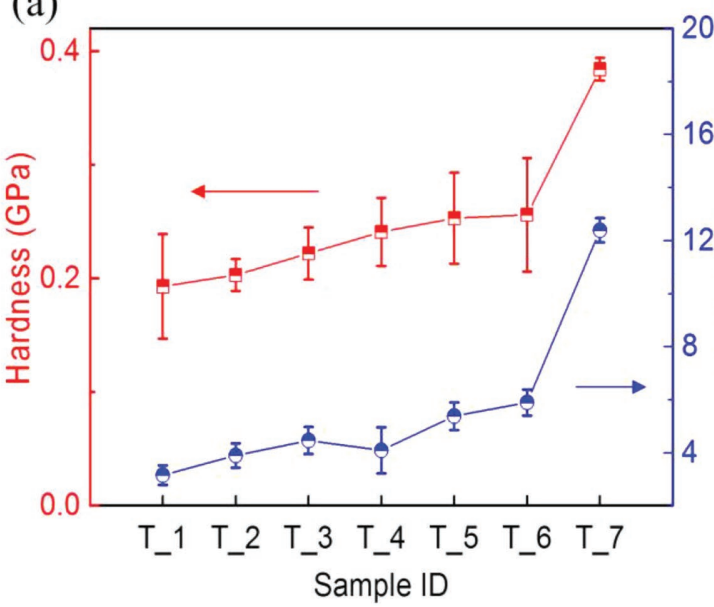

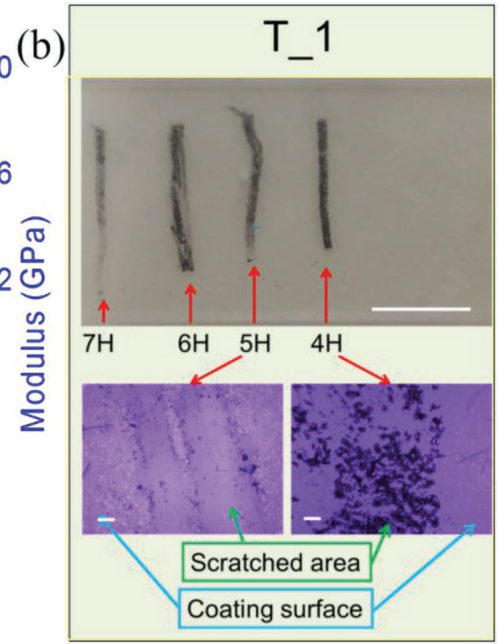

(c)

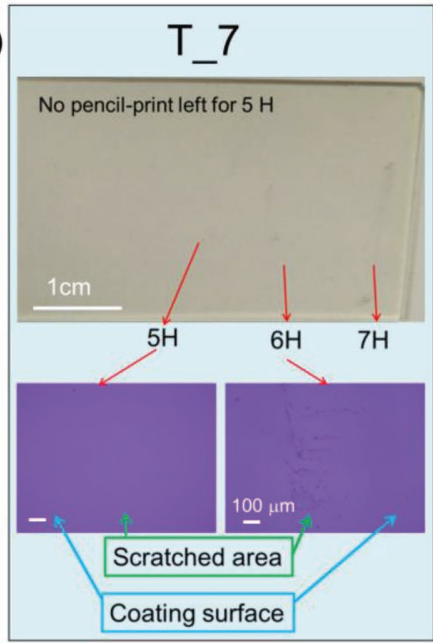

(d)

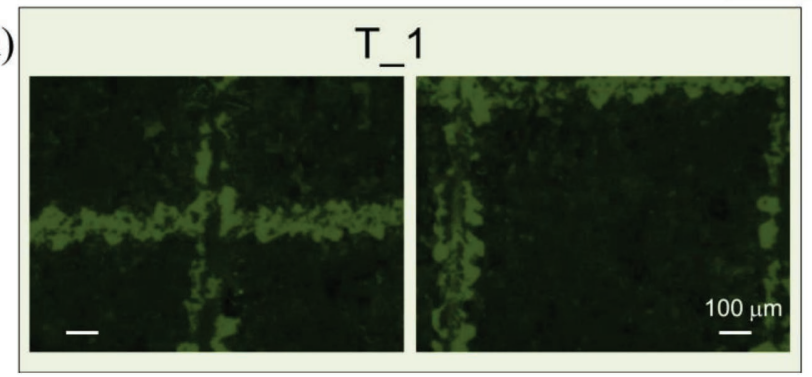

(e)

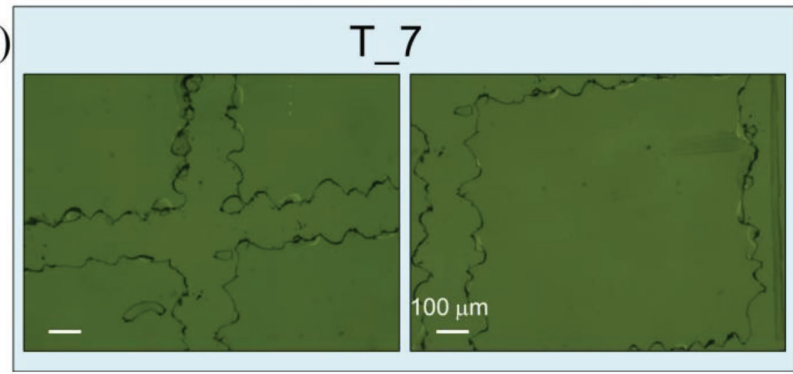

Figure 9. a) Hardness and elastic modulus of titanate nanotube coatings measured with nanoindentation. Research of pencil-scratch test and microscopic observation for b) $T_{-} 1$ and c) T_7 samples and cross-cut tape adhesion test for d) T_1 and e) T_7 samples.

$R_{\mathrm{S}}^{*}\left(T_{i}\right)=\frac{R\left(T_{i}\right)}{S}$

where $S$ is the three-phase contact-line length between the water droplet and the coating surface (schematically illustrated in Figure $8 \mathrm{~g}$ ). It can be calculated as $S=2 \pi r$, where

$r=\left[\frac{3 V}{\pi\left(2-3 \cos \theta+\cos ^{3} \theta\right)}\right]^{1 / 3} \sin \theta$

and $V$ is the volume of the water droplet, and $\theta$ is the apparent contact angle. ${ }^{[3]}$ The corresponding values of $\theta, r$, and $S$ for the uncoated glass, $T_{-} 1$ and $T \_7$ samples are shown in Figure 8g. Consequently, the calculated $R_{\mathrm{S}} *\left(T_{i}\right)$ for these coatings according to Equation (5) are shown in Figure $8 \mathrm{~h}$. At any given temperature, the $T_{-} 7$ sample presented the lowest line ice-nucleation rate, followed by the $T_{-} 1$ sample; both are significantly lower than that of the uncoated glass.

It is believed that heterogeneous ice nucleation occurs more easily on rough surfaces than on flat ones, since the site adsorption and clustering mechanism are rendered less effective when the surface is flat. ${ }^{[34]}$ The T_7 sample is neatly flat, while the $T \_1$ sample is rough; as a result, the $T \_7$ sample presented a lower icing temperature than the T_1 sample. Although the uncoated glass shares similar surface roughness with the $T_{-} 7$ sample, because of its hydrophilic property and high surface energy, a much higher icing temperature than for the T_7 sample is expected.
Even though the ice-adhesion strength of all the samples depends less on surface roughness, the icing-delay time and ice-nucleation temperature are affected significantly by surface roughness. The low ice-nucleation temperature and the delayed icing time of a water droplet on the T_7 sample are important indicators for its anti-icing performance.

\subsection{Mechanical Properties of Titanate Nanotube Coatings}

A major weakness of many existing anti-icing coatings is their poor mechanical performance, which hinders their practical applications. In this work, hardness, scratch resistance, and adhesive properties of the titanate nanotube coatings were investigated according to the ASTM standard. The values of hardness and the elastic modulus of the studied titanate nanotube coatings measured with nanoindentation are given in Figure 9a. An upward trend clearly identifies the increase in hardness and the elasticity modulus of the coatings with the increased stirring time. This is in line with other reports that higher coating roughness and porosity lead to lower values of hardness and modulus. ${ }^{[35]}$ The T_7 sample demonstrated hardness of $380 \pm$ $10 \mathrm{MPa}$ and the elastic modulus of $12.39 \pm 0.46 \mathrm{GPa}$; these are comparable with the values of iCVD film ${ }^{[10]}$ and higher than aeronautical livery icephobic coating. ${ }^{[9]}$ We believe that the excellent mechanical properties are due to (1) better dispersion of nanotubes throughout the coating, and (2) better mechanical reinforcement using a nanotube structure. 
Scratch resistance of the T_1 and the T_7 samples and microscopic images of samples after scratching are compared in Figures $9 \mathrm{~b}$ and $9 \mathrm{c}$. The rough $\mathrm{T} \_1$ sample exhibited pencilscratch resistance of $4 \mathrm{H}$, while the smooth T_7 sample presented $5 \mathrm{H}$ (the pencil-hardness scale ranges from $6 \mathrm{~B}$ for the softest pencil up to $9 \mathrm{H}$ for the hardest), which is significantly higher than the reported icephobic paint ${ }^{[8]}$ and copolymer hybrid film. ${ }^{[7]}$ These results follow the trend of the nanoindentation results. Since the T_1 sample was rough, graphite fragments were left on the coating surface, while nearly no residue was found on the smooth T_7 coating surface. In addition, the T_1 and T_7 samples demonstrated a similar cross-cut adhesion grade at $4 \mathrm{~B}$ (Figure 9d,e), indicating strong adhesion to the substrate. Mechanical studies of the T_7 sample verified its superior mechanical properties compared to the currently reported anti-icing or icephobic coatings. ${ }^{[6-9,36]}$

Optically transparent anti-icing coatings are useful for a wide range of applications where optical transmission is critical, such as solar panels, windows of a house or optical devices, windshield of automobiles, as well as for cases where aesthetic value of the protected objects need to be preserved, such airplanes, wind turbines, sports facilities, and so on. With a transparent coating, the original color of protected objects will not be altered either for aesthetic reasons or due to functional requirements. Together with a higher transmittance, mechanical robustness, and good anti-icing performance, the T_7 sample has a very promising prospective for practically applications in cold regions.

\section{Conclusions}

A transparent anti-icing coating was fabricated employing the elongated titanate nanotubes with a sol-gel method. The coating exhibited good water repellency and anti-icing properties. A significant reduction in the ice-adhesion strength and ice-nucleation temperature was observed. The effect of surface roughness on transparency, water wettability, and icephobicity was also investigated. Although little influence of surface roughness on the ice-adhesion strength was observed, there appears to be a strong effect of surface roughness on the icenucleation process. Our observations confirm ice nucleation along the three-phase contact line regardless of the surface roughness. The produced transparent anti-icing coating demonstrated good hardness and pencil-scratch resistance, as well as excellent adhesion to glass substrates. This mechanically robust anti-icing coating opens a new avenue toward smooth solid coatings for applications in windows, windshields of automobiles, energy-harvesting devices, and aerospace components.

\section{Experimental Section}

Materials: Titanium oxide nanopowder (AEROXIDE $\mathrm{TiO}_{2}$ P25) was obtained from Evonik Industries. Sodium hydroxide pellets, silicone oil, PFOTES, 3-glycidoxypropyltrimethoxysilane (GLYMO), itaconic acid and tetraethylorthosilicate (TEOS), ethylene glycerol, and diiodomethane were purchased from Sigma Aldrich. Microscope glass slides and cover glass (used for ice-nucleation temperature tests) used as substrates were obtained from Sailboat Lab Co., Ltd. and Marienfeld, respectively.

Methods: Fabrication of Titanate Nanotubes: A process of preparation of titanate nanotubes followed the same procedure as reported before. ${ }^{[15]} 0.1 \mathrm{~g}$ titanium oxide nanopowders were ultrasonically mixed with $10 \mathrm{~m}$ sodium hydroxide and stirring magnetically for $24 \mathrm{~h}$, and then transferred to a hydrothermal autoclave, soaked in silicon oil bath and heated at $130^{\circ} \mathrm{C}$ for $24 \mathrm{~h}$ with continuous magnetic stirring. The reaction product was washed with deionized (DI) water and centrifuged for 2-3 times until the $\mathrm{pH}$ value of the particle suspension solution was around 8 . Ultralong sodium titanate nanotubes were obtained, and used as coating fillers.

Fabrication of Anti-Icing Coatings: The resultant titanate nanotubes were dispersed in $10 \mathrm{~mL}$ methanol and modified with $5 \mathrm{~mL}$ of $1 \mathrm{wt} \%$ PFOTES solution. The preparation of PFOTES solution was based on a previous report. ${ }^{[37]}$ The above solution was magnetically stirred for $24 \mathrm{~h}$, then $0.004 \mathrm{~mol}$ TEOS, $0.038 \mathrm{~mol} \mathrm{DI}$ water, and $0.02 \mathrm{~mol}$ GLYMO were added. Itaconic acid was used to acidify the sol to $\mathrm{pH} 4-5$. The sol was first placed in an ultrasonic bath for $30 \mathrm{~min}$, and then magnetically stirred at $500 \mathrm{rpm}$ for different numbers of days until a transparent coating was obtained. The prepared sols were spray-coated onto the glass slides using an airbrush kit (AS06KB) with a $1.5 \mathrm{~mm}$ diameter nozzle under compressed air (at pressure of $345 \mathrm{kPa}$ ). A distance between the airbrush and the substrate was kept at $8 \mathrm{~cm}$. The airbrush was moved laterally back and forth until a uniform coating was deposited. Finally, the prepared samples were cured in an oven at $110^{\circ} \mathrm{C}$ for $1.5 \mathrm{~h}$. The weight percentage of titanate nanotubes in the final coating is $\approx 2.3 \mathrm{wt} \%$, and the thickness of the final coating is around $30 \mu \mathrm{m}$. The resultant coatings were denoted T_1, T_2, T_3, T_4, T_5, T_6, and T_7, the digit represents the number of days during the magnetic stirring of the sols.

Characterization: Surface microstructures of the obtained coatings were examined with a FESEM (JSM-6360, Japan) and AFM (Asylum Research Cypher S, USA). The surface roughness (root mean square, RMS) of coatings was recorded from the AFM measurement. The scanning area was $20 \mu \mathrm{m} \times 20 \mu \mathrm{m}$. The roughness values were averaged from at least five measurements obtained at different locations of the coatings. FTIR spectra of coatings were scanned with Frontier IR/FIR spectrometer (Perkin-Elmer Inc.). The tested coatings were scratched down from the applied substrate and mixed in $\mathrm{KBr}$ powders with a weight ratio of 1:20. Then the mixed powders were compressed into a tablet with a diameter of $10 \mathrm{~mm}$. TEM (JEOL $2100 \mathrm{HR}$, Japan) operating at $200 \mathrm{kV}$ was used to observe the distribution of nanoparticles in the coatings. The transmittance of the coatings was examined by UV-vis spectrophotometer (Shimadzu UV-2501 PC, Japan). Water contact angles and sliding angles were measured with a contact angle system (OCA 20, Dataphysics Co., Germany). Surface energies of coatings were measured following the Owens, Wendt, Rabel, and Kalble (OWRK) method, ${ }^{[38]}$ in which DI water and ethylene glycerol were used as polar liquids, and diiodomethane was used as a nonpolar liquid. The icing delay time was measured at $-15{ }^{\circ} \mathrm{C}$ on a cooling stage of the contactangle measurement system. The glass-substrate samples were directly placed on the cooling stage. A $10 \mu \mathrm{L}$ water droplet was dropped on to sample surface, then the temperature was cooled down and held at $-15{ }^{\circ} \mathrm{C}$. The process of ice nucleation and growth on the water-solid interface was recorded with a high-speed video camera (Phantom Micro 120). The icing delay time of the coating was determined by the time, at which the light reflection of the water droplets suddenly changed from clear and reflective to blurry and nontransparent.

Measurements of ice-adhesion strength between an ice block and coating surfaces followed the scheme from a previous report. ${ }^{[39]}$ In brief, a Teflon mold filled with DI water was covered with a coated substrate on top, and then the whole setup was placed upside down and stored in a climate chamber (Cincinnati Sub-Zero environmental chambers, USA) for $24 \mathrm{~h}$ at $-20{ }^{\circ} \mathrm{C}$. The ice-nucleation temperature of coatings was studied using the previously reported home-designed automatic ice nucleation measurement system. ${ }^{[40]}$ The system utilizes a laser beam and an optical detector to record the freezing events. In this experiment, a $10 \mu \mathrm{L} \mathrm{DI}$ water droplet was placed on the coating surface, and then cooled down from 22 to $-30{ }^{\circ} \mathrm{C}$. The ramp rate from 22 to $0{ }^{\circ} \mathrm{C}$ was set at $40{ }^{\circ} \mathrm{C} \mathrm{min}-1$, while the ramp rate from 0 to $-30{ }^{\circ} \mathrm{C}$ was set as $5{ }^{\circ} \mathrm{C} \mathrm{min}^{-1}$. Once the whole cycle was completed, the iced droplet was warmed up to $22{ }^{\circ} \mathrm{C}$ and held for 2 min to ensure a complete melting 
of the ice droplet before the next cycle began. Icing temperatures of 500 cycles for each water droplet were recorded and statistically analyzed.

A pencil-scratch test was made using a commercial pencil-scratch tester (Scratch Hardness Tester Model 291, ERICHSEN) according to ASTM D3363 standard. The coating quality was measured by cross-cut adhesion test, which was based on the ASTM D3359 standard. After cross cutting, the coatings were examined under an optical microscope (Olympus BX51). The elastic modulus and hardness of the coatings were measured using a nanoindentator (Nano-Indentation \& MicroScratch System, Wrexham, UK). Readings were made at indentation depth from 1800 to $2000 \mathrm{~nm}$. For each specimen, 15 points (in 3 lines, 5 points for each line) were tested.

\section{Supporting Information}

Supporting Information is available from the Wiley Online Library or from the author.

\section{Acknowledgements}

This work was supported by Nanyang Technological University in form of a research scholarship, and the Agency for Science, Technology and Research (A*STAR) of Singapore (SERC 1528000048).

\section{Conflict of Interest}

The authors declare no conflict of interest.

\section{Keywords}

anti-icing, mechanical properties, sol-gel, titanate nanotubes, transparent

[1] T. Maitra, S. Jung, M. E. Giger, V. Kandrical, T. Ruesch, D. Poulikakos, Adv. Mater. Interfaces 2015, 2, 1500330.

[2] T. S. Wong, S. H. Kang, S. K. Tang, E. J. Smythe, B. D. Hatton, A. Grinthal, J. Aizenberg, Nature 2011, 477, 443.

[3] a) M. J. Kreder, J. Alvarenga, P. Kim, J. Aizenberg, Nat. Rev. Mater. 2016, 1, 15003; b) T. Furuta, M. Sakai, T. Isobe, A. Nakajima, Langmuir 2010, 26, 13305; c) K. Golovin, S. P. Kobaku, D. H. Lee, E. T. DiLoreto, J. M. Mabry, A. Tuteja, Sci. Adv. 2016, 2, e1501496; d) X. Wu, S. Zheng, D. A. Bellido-Aguilar, V. V. Silberschmidt, Z. Chen, Mater. Des. 2018, 140, 516.

[4] N. Wang, D. Xiong, Y. Deng, Y. Shi, K. Wang, ACS Appl. Mater. Interfaces 2015, 7, 6260.

[5] J. Chen, R. Dou, D. Cui, Q. Zhang, Y. Zhang, F. Xu, X. Zhou, J. Wang, Y. Song, L. Jiang, ACS Appl. Mater. Interfaces 2013, 5, 4026.

[6] R. Menini, Z. Ghalmi, M. Farzaneh, Cold Reg. Sci. Technol. 2011, 65, 65.

[7] Y. Huang, M. Hu, S. Yi, X. Liu, H. Li, C. Huang, Y. Luo, Y. Li, Thin Solid Films 2012, 520, 5644.

[8] S. Kimura, Y. Yamagishi, A. Sakabe, T. Adachi, M. Shimanuki, SAE Technical Paper 2001-01-3315, 2007, p. 9.

[9] L. Mazzola, Surf. Eng. 2016, 32, 733.

[10] H. Sojoudi, G. H. McKinley, K. K. Gleason, Mater. Horiz. 2015, 2, 91.

[11] C. Antonini, M. Innocenti, T. Horn, M. Marengo, A. Amirfazli, Cold Reg. Sci. Technol. 2011, 67, 58.

[12] A. F. Gross, A. P. Nowak (HRL Laboratories LLC), US 15/718, 181, 2018.

[13] a) Y. Tang, Y. Zhang, X. Rui, D. Qi, Y. Luo, W. R. Leow, S. Chen, J. Guo, J. Wei, W. Li, Adv. Mater. 2016, 28, 1567; b) Y. Zhang, O. I. Malyi, Y. Tang, J. Wei, Z. Zhu, H. Xia, W. Li, J. Guo, X. Zhou,
Z. Chen, Angew. Chem. 2017, 129, 15043; c) Y. Tang, Y. Zhang, J. Deng, D. Qi, W. R. Leow, J. Wei, S. Yin, Z. Dong, R. Yazami, Z. Chen, Angew. Chem., Int. Ed. 2014, 53, 13488.

[14] Y. Lai, Y. Tang, J. Gong, D. Gong, L. Chi, C. Lin, Z. Chen, J. Mater. Chem. 2012, 22, 7420.

[15] Y. Tang, Y. Zhang, J. Deng, J. Wei, H. L. Tam, B. K. Chandran, Z. Dong, Z. Chen, X. Chen, Adv. Mater. 2014, 26, 6111.

[16] a) L. Zheng, Z. Li, S. Bourdo, K. R. Khedir, M. P. Asar, C. C. Ryerson, A. S. Biris, Langmuir 2011, 27, 9936; b) O. Gohardani, M. C. Elola, C. Elizetxea, Prog. Aerosp. Sci. 2014, 70, 42.

[17] A. Cassie, S. Baxter, J. Chem. Soc., Faraday Trans. 1944, 40, 546.

[18] S. Amoriello, A. Bianco, L. Eusebio, P. Gronchi, J. Sol-Gel Sci. Technol. 2011, 58, 209.

[19] a) H. Zhang, X. Lv, Y. Li, Y. Wang, J. Li, ACS Nano 2009, 4, 380; b) H. Zuo, J. Sun, K. Deng, R. Su, F. Wei, D. Wang, Chem. Eng. Technol. 2007, 30, 577.

[20] S. Pazokifard, S. M. Mirabedini, M. Esfandeh, S. Farrokhpay, Adv. Powder Technol. 2012, 23, 428.

[21] P. Innocenzi, A. Martucci, M. Guglielmi, L. Armelao, S. Pelli, G. Righini, G. Battaglin, J. Non-Cryst. Solids 1999, 259, 182.

[22] E. Lataste, A. Demourgues, H. Leclerc, J.-M. Goupil, A. Vimont, E. Durand, C. Labrugère, H. Benalla, A. Tressaud, J. Phys. Chem. C 2008, 112, 10943.

[23] a) B. J. Basu, J. Manasa, J. Colloid Interface Sci. 2011, 363, 655; b) M. Hikita, K. Tanaka, T. Nakamura, T. Kajiyama, A. Takahara, Langmuir 2005, 21, 7299; c) R. Kasemann, H. Schmidt, New J. Chem. 1994, 8, 1117.

[24] K. C. Chang, Y. K. Chen, H. Chen, J. Appl. Polym. Sci. 2008, 107, 1530.

[25] V. Hejazi, K. Sobolev, M. Nosonovsky, Sci. Rep. 2013, 3.

[26] a) O. Gohardani, D. W. Hammond, Cold Reg. Sci. Technol. 2013, 96, 8; b) Y. Wang, J. Xue, Q. Wang, Q. Chen, J. Ding, ACS Appl. Mater. Interfaces 2013, 5, 3370.

[27] a) A. Dotan, H. Dodiuk, C. Laforte, S. Kenig, J Adhes. Sci. Technol. 2009, 23, 1907; b) A. J. Meuler, J. D. Smith, K. K. Varanasi, J. M. Mabry, G. H. McKinley, R. E. Cohen, ACS Appl. Mater. Interfaces 2010, 2, 3100; c) Y. H. Yeong, J. Sokhey, E. Loth, Advances in Polymer Science, Spinger, Berlin 2017, pp. 1-23.

[28] R. Menini, M. Farzaneh, J. Adhes. Sci. Technol. 2011, 25, 971.

[29] M. Nosonovsky, V. Hejazi, ACS Nano 2012, 6, 8488.

[30] H. A. Stone, ACS Nano 2012, 6, 6536.

[31] a) Q. T. Fu, E. J. Liu, P. Wilson, Z. Chen, Phys. Chem. Chem. Phys. 2015, 17, 21492; b) S. Suzuki, A. Nakajima, N. Yoshida, M. Sakai, A. Hashimoto, Y. Kameshima, K. Okada, Chem. Phys. Lett. 2007, 445,37 ; c) C. W. Gurganus, J. C. Charnawskas, A. B. Kostinski, R. A. Shaw, Phys. Rev. Lett. 2014, 113, 235701.

[32] P. Wilson, A. Heneghan, A. Haymet, Cryobiology 2003, 46, 88.

[33] P. Hao, C. Lv, X. Zhang, Appl. Phys. Lett. 2014, 104, 161609.

[34] D. Bassett, E. Boucher, A. Zettlemoyer, J. Colloid Interface Sci. 1970, $34,436$.

[35] a) C. C. Gonzaga, P. F. Cesar, C. Y. Okada, C. Fredericci, F. B. Neto, H. N. Yoshimura, Mater. Res. 2008, 11, 301; b) O. Sarikaya, Surf. Coat. Technol. 2005, 190, 388; c) Q. Yang, T. Senda, A. Ohmori, Wear 2003, 254, 23.

[36] R. Menini, M. Farzaneh, Surf. Coat. Technol. 2009, 203, 1941.

[37] X. Wu, Q. Fu, D. Kumar, J. W. C. Ho, P. Kanhere, H. Zhou, Z. Chen, Mater. Des. 2016, 89, 1302.

[38] a) D. K. Owens, R. Wendt, J. Appl. Polym. Sci. 1969, 13, 1741; b) D. Kaelble, J. Adhes. Adhes. 1970, 2, 66; c) W. Rabel, Farbe Lack 1971, 77, 997.

[39] Q. Fu, X. Wu, D. Kumar, J. W. Ho, P. D. Kanhere, N. Srikanth, E. Liu, P. Wilson, Z. Chen, ACS Appl. Mater. Interfaces 2014, 6, 20685.

[40] a) T. Verho, C. Bower, P. Andrew, S. Franssila, O. Ikkala, R. H. A. Ras, Adv. Mater. 2011, 23, 673; b) P. Judeinstein, C. Sanchez, J. Mater. Chem. 1996, 6, 511. 